\footnotetext{
1 Primary Healthcare Research Unit, Faculty of Medicine, Memorial University of Newfoundland, St John's, Newfoundland A1B 3V6, Canada

2 Institute for Musculoskeletal Health, University of Sydney and Sydney Local Health District, Sydney, Australia

Correspondence to: A M Hall amanda.Hall@med.mun.ca

Cite this as: BMJ 2021;372:n291 http://dx.doi.org/10.1136/bmi.n291 Published: 12 February 2021
}

\title{
CHANGE
}

\section{Do not routinely offer imaging for uncomplicated low back pain}

\author{
Amanda M Hall, ${ }^{1}$ Kris Aubrey-Bassler, ${ }^{1}$ Bradley Thorne, ${ }^{1}$ Chris G Maher ${ }^{2}$
}

\section{What you need to know}

- Less than $5-10 \%$ of all low back pain is due to a specific underlying spinal pathology

- The remaining 90-95\% has no indication of a serious cause and should be managed with conservative treatments such as advice and reassurance, exercise, physical therapy, chiropractic care, cognitive-behavioural therapy, or pain management

- Diagnostic triage based on clinical history and examination can help distinguish between non-specific or more serious low back pain

- Imaging may do more harm than good when serious conditions are not suspected and is likely to prolong recovery in patients with non-specific low back pain

- Patients' primary concerns of whether their pain is caused by something serious and what they should do to aid recovery can be addressed by sound education and reassurance, without the need for imaging

\section{The clinical problem}

The past two decades have seen a paradigm shift in the way we use imaging when managing low back pain (LBP). Imaging was once a routine part of the diagnostic workup for most cases of LBP. Evidence now indicates that imaging is useful only in the small subgroup of patients for whom there is suspicion of red flag conditions. These conditions include cancer, infection, inflammatory disease, fracture, and severe neurological deficits-which together account for only 5-10\% of LBP presentations in primary care. ${ }^{1}$ For the remaining 90-95\% of LBP cases (called non-specific or uncomplicated LBP), imaging will not guide management and can cause more harm than benefit. International guidelines ${ }^{2}$ and "Choosing Wisely” campaigns now encourage a diagnostic triage approach to identify those patients who require imaging (box 1). Given these advances in knowledge, imaging rates for LBP should be decreasing, but recent systematic reviews show the opposite, reporting that imaging has increased over the past 20 years $^{3}$ and that at least a third of all images are unnessary. ${ }^{4}$
Box 1: "Choosing Wisely" statements from different countries related to avoiding the use of routine imaging for low back pain

- “Don't routinely image patients with low back pain regardless of the duration of symptoms unless: (a) there are clinical reasons to suspect serious underlying pathology (i.e., red flags), or (b) imaging is necessary for the planning and/or execution of a particular evidenced-based therapeutic intervention on a specific spinal condition."-Canadian Spine Society, Choosing Wisely Canada

- "Do not undertake imaging for low back pain in patients without indications of a serious underlying condition."-Australian Rheumatology Association, Choosing Wisely Australia

- "Do not routinely offer imaging in a non-specialist setting for people with low back pain with or without sciatica. Consider imaging in specialist settings of care (for example, a musculoskeletal interface clinic or hospital) for people with low back pain with or without sciatica only if the result is likely to change management."-Royal College of Physicians, Choosing Wisely UK

\section{The evidence for change}

Evidence from randomised controlled trials has established that imaging does not improve clinical outcomes, and several observational studies have linked liberal imaging with greater work absence and unnecessary use of health services. ${ }^{5}$ Unnecessary LBP imaging has the potential for harm. Perhaps the most obvious of these harms is exposure to radiation from $\mathrm{x}$ rays and computed tomography. Harm is also possible if a clinician acts on incidental findings from any imaging method, including magnetic resonance imaging (MRI), or if these findings are not appropriately explained to patients. For example, disc abnormalities such as bulging disc or degenerative disc disease are commonly seen on images but may not be the source of pain, as they are also seen on images in up to $97 \%$ of asymptomatic patients (table 1). ${ }^{6}$ Incidental findings may lead to further investigations, specialist referral, and more intensive treatment such as surgery, which limits access to those services for the patients who are in genuine need of such care. ${ }^{7}$ Incidental findings may also provoke worry or concern in patients from a labelling effect (possibly delaying recovery) if they fail to understand that these anomalies are common and benign. 89 
Table 1 | Age-specific prevalence estimates of degenerative spine imaging findings in asymptomatic people ${ }^{6}$

\begin{tabular}{|c|c|c|c|c|c|c|c|}
\hline \multirow[b]{2}{*}{ Image finding } & \multicolumn{7}{|c|}{ Prevalence (\%) of findings by age (years) } \\
\hline & 20 & 30 & 40 & 50 & 60 & 70 & 80 \\
\hline Disc degeneration & 37 & 52 & 68 & 80 & 88 & 93 & 96 \\
\hline Disc height loss & 24 & 34 & 45 & 56 & 67 & 76 & 84 \\
\hline Disc bulge & 30 & 40 & 50 & 60 & 69 & 77 & 84 \\
\hline Disc protrusion & 29 & 31 & 33 & 36 & 38 & 40 & 43 \\
\hline Facet degeneration & 4 & 9 & 18 & 32 & 50 & 69 & 83 \\
\hline Spondylolisthesis & 3 & 5 & 8 & 14 & 23 & 35 & 50 \\
\hline
\end{tabular}

Imaging and follow-up based on incidental findings affects the health system in terms of direct costs (such as cost of equipment, staff time to conduct the imaging, and time to interpret the image findings) and downstream costs (subsequent tests, referrals, and interventions, many of which are expensive and are of limited benefit for most patients with back pain). The downstream costs of imaging also affect patients and society due to indirect costs relating to out of pocket expenses for unnecessary interventions, as well as expenses related to lost work or household productivity. ${ }^{810}$ Two systematic reviews of six randomised controlled trials (1804 participants) both concluded that patients who received imaging without a clear clinical indication did not have improvements to pain, function, or quality of life compared with those who did not have imaging. ${ }^{11}{ }^{12}$ Additionally, observational studies have found that those who received imaging when not indicated had greater use of health services such as injections and surgery and greater work absence than their counterparts who did not receive imaging. . $^{13^{-15}}$ For example, a 2020 study of 405965 US primary care patients found that those who had early MRI were more likely to undergo back surgery $(1.48 \% v 0.12 \%)$ and take prescription opioids (35.1\% v 28.6\%), yet had higher pain score at 1-year follow-up (3.99 $v$ 3.87) than those who did not get early MRI. ${ }^{16}$

\section{Barriers to change}

Lack of awareness of current back pain guidelines and knowledge about how to apply them in practice are likely contributors to the over-reliance on imaging in primary care. This is often exacerbated if institutional policies and practices around imaging are not aligned to the latest evidence. Recent systematic reviews suggest that the clinical environment itself may encourage physicians to over-order imaging due to $(a)$ accommodating patient requests, $(b)$ believing that imaging will reassure the patient, and $(c)$ not having time to explain and justify a non-imaging approach. ${ }^{17}$ Reported less consistently in the literature, additional factors include worry about missing a specific pathology, not being aware of conservative interventions besides medication, and a lack of access to conservative management such as exercise therapy, physical therapy, chiropractic care, cognitive behavioural therapy, and pain management programmes. ${ }^{1718}$

\section{Patient perspectives}

Clinicians often report that they order imaging when patients specifically request it. Systematic reviews of surveys and interviews suggest that about half of patients expect imaging from their health provider because they believe it can help rule out a sinister cause for the pain. ${ }^{19}$ Some patients also believe that imaging can identify the cause better than the clinician's physical exam and facilitate a more tailored approach to treatment. ${ }^{19}$ There is still considerable uncertainty as to what alternatives to imaging would convey the diagnosis of non-specific LBP satisfactorily from the patient's perspective. Future research should focus on this area to develop strategies for explaining LBP to patients.

\section{How should practice change?}

Practice changes in the following key areas are required to support appropriate imaging use:

Diagnostic triage and management-Evidence suggests that, by conducting a more thorough diagnostic triage, ${ }^{20}$ clinicians can discern which patients fall into the category of non-specific LBP. Papers by Bardin et $\mathrm{al}^{20}$ and Traegar et $\mathrm{al}^{21}$ present a useful visual aid (fig 1) for conducting diagnostic triage in patients with LBP. Bardin et al's visual aid also details evidence based treatments for patients assessed to have radicular syndrome or non-specific LBP. We have supplemented this with a decision support tool (fig 2) to help clinicians identify the small subgroup of patients with suspected red flag conditions who do need imaging. As detailed in figure 1, advise all patients with non-specific LBP or radicular syndromes, regardless of pain duration, to remain active and reassure them of a good prognosis. 


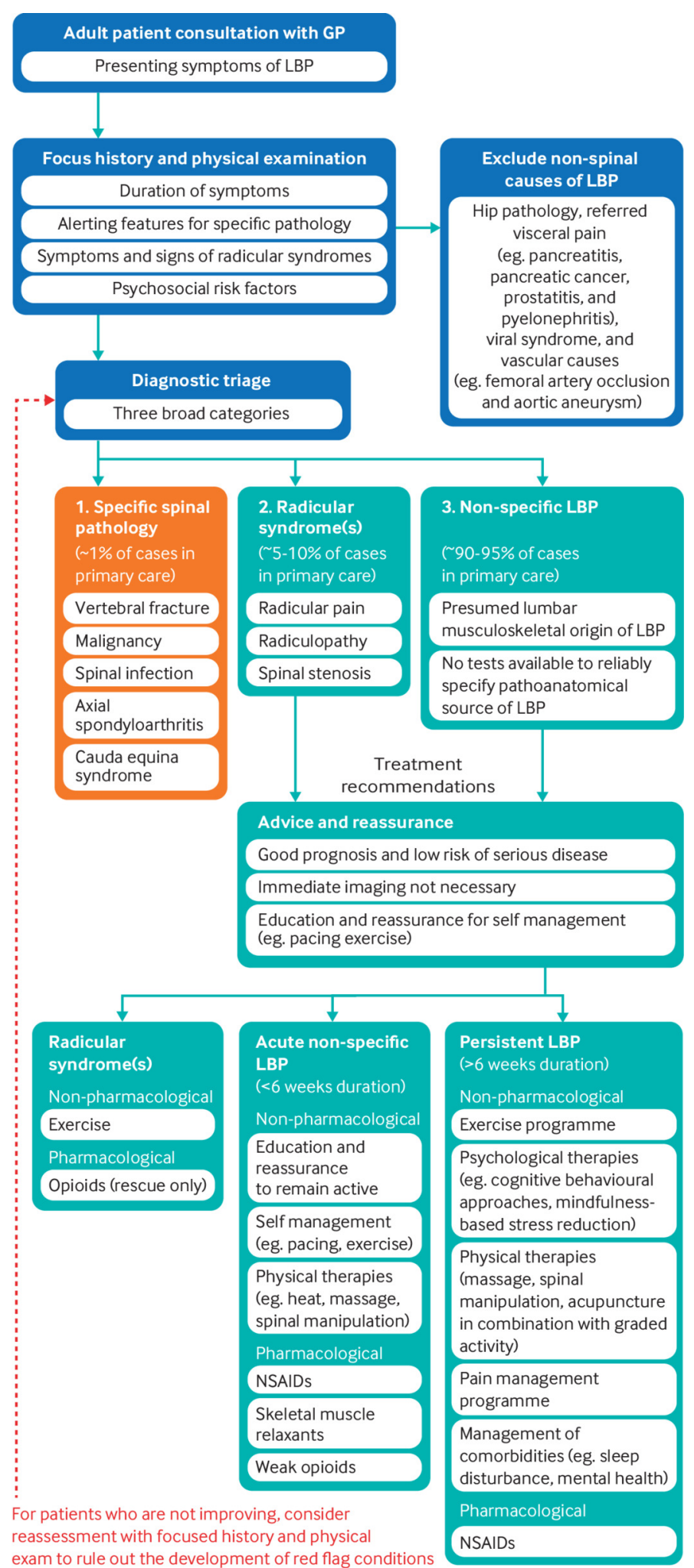

LBP = low back pain, NSAIDs = non-steroidal anti-inflammatory drugs

Fig 1 | Diagnostic triage for low back pain. (Adapted from Traegar et $\mathrm{al}^{21}$ ) 


\begin{tabular}{|c|c|c|c|}
\hline Alerting features & Diagnosis and prevalence & Image type & Timing \\
\hline Older age ( $>65$ years for men, $>75$ years for women) & \multirow{4}{*}{ Vertebral fracture $0.7 \%-4.5 \%$} & \multirow{4}{*}{$\mathrm{X}$ ray possible $\mathrm{CT}$ scan } & Major risk: immediate \\
\hline Prolonged corticosteroid use & & & Minor risk: 1 month \\
\hline Severe trauma & & & "watch and wait" \\
\hline \multicolumn{2}{|l|}{ Presence of contusion or abrasion } & & \\
\hline History of malignancy & \multirow{3}{*}{ Malignancy $0.2 \%$} & \multirow{3}{*}{$\mathrm{X}$ ray and MRI } & Major risk: immediate \\
\hline Strong clinical suspicion & & & Minor risk: delay \\
\hline Unexplained weight loss, $>50$ years & & & \\
\hline Fever or chills & \multirow{5}{*}{ Spinal infection $0.01 \%$} & \multirow{5}{*}{$\mathrm{X}$ ray and MRI } & Immediate \\
\hline Immune compromised patient & & & \\
\hline Pain at rest or at night & & & \\
\hline Intravenous drug user & & & \\
\hline Recent injury, dental or spine procedure & & & \\
\hline New bowel or bladder dysfunction & \multirow{3}{*}{ Cauda equina syndrome $0.04 \%$} & \multirow{3}{*}{ MRI } & Immediate \\
\hline Perineal numbness or saddle anaesthesia & & & \\
\hline Persistent or progressive lower motor neuron changes & & & \\
\hline Progressive lower limb motor weakness & \multirow{2}{*}{ Severe neurologic deficits } & \multirow{2}{*}{ MRI } & Immediate \\
\hline Motor deficits at multiple levels & & & \\
\hline $\begin{array}{l}\text { Chronic back pain ( }>3 \text { months' duration), with back } \\
\text { pain onset before } 45 \text { years of age and one or more } \\
\text { of the following }\end{array}$ & \multirow{6}{*}{$\begin{array}{l}\text { Axial spondyloarthirtis } \\
0.1 \%-1.4 \%\end{array}$} & \multirow{6}{*}{\multicolumn{2}{|c|}{$\begin{array}{l}\text { Refer to rheumatologist } \\
\text { if strong suspicion of axial } \\
\text { spondyloarthritis }\end{array}$}} \\
\hline $\begin{array}{l}\text { Inflammatory back pain with at least } 4 \text { of: } \\
\text { - Age of onset } 40 \text { years or younger } \\
\text { - Insidious onset } \\
\text { - Improvement with exercise } \\
\text { - No improvement with rest } \\
\text { - Pain at night - with improvement when getting up }\end{array}$ & & & \\
\hline $\begin{array}{l}\text { Peripheral manifestations (in particular arthritis, } \\
\text { enthesitis, or dactylitis) }\end{array}$ & & & \\
\hline $\begin{array}{l}\text { Extra-articular manfestation (psoriasis, inflammatory } \\
\text { bowel disease, or uveitis) }\end{array}$ & & & \\
\hline Positive family history of spondyloarthritis & & & \\
\hline Good response to NSAIDs & & & \\
\hline
\end{tabular}

\begin{tabular}{|c|c|c|c|}
\hline Alerting features & nosis and prevalence & Image type & Timing \\
\hline $\begin{array}{l}\text { Back pain with leg pain in an L4, L5, or S1 nerve root } \\
\text { distribution }\end{array}$ & \multirow{2}{*}{ Radicular pain or radiculopathy } & \multirow{2}{*}{$\begin{array}{l}\text { Consider MRI in patients who } \\
\text { are candidates for surgery }\end{array}$} & \multirow{2}{*}{$\begin{array}{l}\text { Defer work up until a } \\
\text { trial of therapy has been } \\
\text { completed }\end{array}$} \\
\hline $\begin{array}{l}\text { Positive result on straight leg raise or crossed } \\
\text { straight leg raise twist }\end{array}$ & & & \\
\hline Bilateral buttock, thigh, or leg pain & \multirow{3}{*}{ Spinal canal stenosis } & \multirow{3}{*}{$\begin{array}{l}\text { Consider MRI in patients who } \\
\text { are candidates for surgery }\end{array}$} & \multirow{3}{*}{$\begin{array}{l}\text { Defer work up until a } \\
\text { trial of therapy has been } \\
\text { completed }\end{array}$} \\
\hline Older age & & & \\
\hline Pseudoclaudication & & & \\
\hline
\end{tabular}

$\mathrm{CT}=$ computed tomography, MRI = magnetic resonance imaging, NSAIDs = non-steroidal anti-inflammatory drugs

Fig 2 | Decision aid based on the latest evidence for triaging LBP patients. (Imaging for all other conditions is probably not useful and may be harmful.) (Adapted from Bardin et $\mathrm{al}^{20}$ )

Patient education-Offer patients with non-specific LBP reassurance that imaging is not required and provide advice on self management as first-line care. Box 2 summarises key points to cover when providing reassurance. Jenkins et al's education booklet Understanding My Low Back Pain guides clinicians and patients through points to cover within a consultation ${ }^{22}$ and can be given to 
patients as an educational and treatment advice tool (see fig 3 for an example).

\section{Box 2: What patients need to know}

- Most cases of LBP are simple strains and sprains of the back that, while painful and unpleasant, improve rapidly just like a sprained ankle

- Having an image (x ray or CT or MRI scan) of your back does not usually help to find the cause of the back pain or guide treatment
- The treatment for most cases of back pain is the same whether imaging is used or not; and we have seen that those who have unnecessary imaging often have a delayed recovery

- Unnecessary imaging has some risks, including radiation exposure and delay in appropriate treatment, and has been associated with worse patient outcomes and an increase in unnecessary surgery

- You may know other people who have had an x ray, CT, or MRI of their back that showed "changes"; but most of the changes seen on imaging are normal and are more common the older you get, just like grey hair and wrinkles. As these changes also occur in people without back pain, their relevance is unclear 


\section{Why isn't imaging needed?}

Imaging (eg, x-rays, CTs or MRI scans) doesn't usually help find the cause of pain.

The treatment and speed of recovery for most cases of back pain is the same whether imaging is used or not.

\section{WON'TIMAGING SHOW WHAT IS CAUSING MY LOW BACK PAIN?}

No - the underlying cause of back pain cannot usually be seen on imaging.

Imaging can help diagnose serious causes of low back pain - but, these are very rare and your GP will check for signs of them.

\section{KNOW OTHER PEOPLE WHO FOUND} 'CHANGES' ON IMAGING OF THEIR BACK WHAT IF I HAVE THESE 'CHANGES' TOO?

Many 'changes' can be seen on imaging, but it is unknown if they are causing your pain.

Most of the 'changes' seen on imaging are normal and more common the older you get.

Even people without back pain commonly have imaging 'changes'. For example, 6 out of 10 middle aged people without back pain have changes on imaging such as disc bulges or degeneration.
WHY SHOULDN'T I GET IMAGING 'JUST IN CASE'?

Unnecessary imaging has some risks:

- Radiation exposure (for X-ray and CT) can increase the risk of cancer. Less radiation is better

- It can cost you money and is time consuming

- Changes on imaging are often seen and may cause stress, anxiety and worry, even though they are usually unimportant

- Imaging has been associated with worse patient outcomes and an increase in unnecessary surgery

Fig 3 | Screenshot from patient education booklet Understanding My Low Back Pain provided as a data supplement by Jenkins et al ${ }^{22}$ (available at: https://www.ncbi.nlm.nih.gov/pmc/articles/PMC6154885/bin/12913_2018_3526_MOESM3_ESM.pdf)

Communication style-Findings from a recent qualitative study suggests four key behaviours from clinicians that can help patients feel reassured. ${ }^{23}$
- Show that you "know the whole story" by summarising the patient's medical history and conducting a thorough assessment 
- Demonstrate empathy and communicate that you are qualified and experienced, helping the patient to feel that they are "seeing the right person"

- Reduce the use of generic statements such as "nothing to worry about" and recognise the patient's distress

- Explain the likely cause(s) of LBP and provide a clear self management plan to help the patient understand and manage their LBP. ${ }^{22}$

Monitoring-Regularly monitor image ordering practices and LBP outcomes relative to peers. This will reassure clinicians that the changes to practice that they implement are effective and do not result in patient harm.

\section{Search methods}

We searched Medline and the Cochrane Library to identify published systematic reviews on (i) the use of LBP imaging, (ii) the concordance of imaging with guidelines, (iii) physician reported barriers to guideline adherence, (iv) patient expectations around LBP imaging, and (v) interventions that have been used to change LBP imaging practice. Additionally, we consulted experts in LBP and primary care on relevant published evidence and the most up to date LBP guidelines internationally.

\section{Education into practice}

- How will your referrals for imaging in people with low back pain change as a result of reading this article?

- Audit the number of spinal $x$ rays and MRIs requested in your practice in the past six months. How many of those imaging requests are in line with the recommendations given in the diagnostic triage tool in fig 1 ?

- How might you go about providing reassurance that imaging is not required?

\section{How patients were involved in the creation of this article}

Bradley Thorne is a patient advisor for the Primary Healthcare Research Unit Musculoskeletal Programme at Memorial University, Newfoundland. In this role, he has consulted on several projects related to improving the management of LBP. He has a special interest in back pain due to lived experiences with low back pain over many years. He reviewed a range of publicly available patient facing materials, as well as the published literature that informed the "Patient perspectives" section in addition to reviewing and commenting on subsequent versions of the manuscript.

We thank Helen Richmond (postdoctoral fellow) and Andrea Pike (senior research assistant) at the Faculty of Medicine, Memorial University for their assistance with searching the literature and reviewing the manuscript. We thank Wendy Levinson and Karen Born for suggesting the review topic and reviewing the manuscript.

Contributors: AH conducted the initial literature review (which was reviewed by KA and CM) and prepared the first draft of the article. BT reviewed the result from the literature search relating to the patients perspective. BT also reviewed the "Patients perspectives" section and reviewed literature specific to patients and public knowledge of and attitudes toward back pain imaging. KA and CM reviewed and revised the manuscript. $\mathrm{AH}$ is the guarantor for the paper.

Competing interests: We have read and understood the BMJ Group policy on declaration of interests and have no relevant interests to declare.

Provenance and peer review: Commissioned, based on an idea from the author; externally peer reviewed.

Henschke N, Maher CG, Refshauge KM, etal. Prevalence of and screening for serious spinal pathology in patients presenting to primary care settings with acute low back pain. Arthritis Rheum 2009;60:3072-80. doi: 10.1002/art.24853 pmid: 19790051
2 O'Connell NE, Cook CE, Wand BM, Ward SP. Clinical guidelines for low back pain: A critical review of consensus and inconsistencies across three major guidelines. Best Pract Res Clin Rheumatol 2016;30:968-80. doi: 10.1016/j.berh.2017.05.001 pmid: 29103554

3 Downie $\mathrm{A}$, Hancock $\mathrm{M}$, Jenkins $\mathrm{H}$, etal. How common is imaging for low back pain in primary and emergency care? Systematic review and meta-analysis of over 4 million imaging requests across 21 years. BrJ Sports Med2020;54:642-51. doi: 10.1136/bjsports-2018-100087 pmid: 30760458

4 Jenkins HJ, Downie AS, Maher CG, Moloney NA, Magnussen JS, Hancock MJJTS. Imaging for low back pain: is clinical use consistent with guidelines? A systematic review and meta-analysis. Spine J2018;18:2266-77. doi: 10.1016/j.spinee.2018.05.004 pmid: 29730460

5 Maher C, Underwood M, Buchbinder R. Non-specific low back pain. Lancet 2017;389:736-47. doi: 10.1016/S0140-6736(16)30970-9 pmid: 27745712

6 Brinjikji W, Luetmer PH, Comstock B, etal. Systematic literature review of imaging features of spinal degeneration in asymptomatic populations. AJNR Am J Neuroradiol 2015;36:811-6. doi: 10.3174/ajnr.A4173 pmid: 25430861

7 Ganguli I, Simpkin AL, Lupo C, etal. Cascades of care after incidental findings in a US national survey of physicians. JAMA Netw Open 2019;2:e1913325-1913325. doi: 10.1001/jamanetworkopen.2019.13325 . pmid: 31617925

8 Chou R, Deyo RA, Jarvik JG. Appropriate use of lumbar imaging for evaluation of low back pain. Radiol Clin North Am 2012;50:569-85. doi: 10.1016/j.rcl.2012.04.005 pmid: 22643385

9 Fisher ES, Welch HG. Avoiding the unintended consequences of growth in medical care: how might more be worse?JAMA 1999;281:446-53. doi: 10.1001/jama.281.5.446 pmid: 9952205

10 Chou R, Qaseem A, Owens DK, Shekelle PClinical Guidelines Committee of the American College of Physicians. Diagnostic imaging for low back pain: advice for high-value health care from the American College of Physicians. Ann Intern Med 2011;154:181-9. doi: 10.7326/0003-4819-154-3-201102010-00008 pmid: 21282698

11 Lemmers GPG, van Lankveld W, Westert GP, van der Wees PJ, Staal JB. Imaging versus no imaging for low back pain: a systematic review, measuring costs, healthcare utilization and absence from work. Eur Spine /2019:28:937-50.

doi: 10.1007/s00586-019-05918-1 pmid: 30796513

12 Chou R, Fu R, Carrino JA, Deyo RA. Imaging strategies for low-back pain: systematic review and meta-analysis. Lancet2009;373:463-72. doi: 10.1016/S0140-6736(09)60172-0 pmid: 19200918

13 Webster BS, Cifuentes M. Relationship of early magnetic resonance imaging for work-related acute low back pain with disability and medical utilization outcomes. J Occup Environ Med 2010:52:900-7. doi: 10.1097/JOM.0b013e3181ef7e53 pmid: 20798647

14 Webster BS, Bauer AZ, Choi Y, Cifuentes M, Pransky GS. latrogenic consequences of early magnetic resonance imaging in acute, work-related, disabling low back pain. Spine (Phila Pa 1976) 2013;38:1939-46. doi: 10.1097/BRS.0b013e3182a42eb6 pmid: 23883826

15 Graves JM, Fulton-Kehoe D, Jarvik JG, Franklin GM. Health care utilization and costs associated with adherence to clinical practice guidelines for early magnetic resonance imaging among workers with acute occupational low back pain. Health Serv Res 2014;49:645-65. doi: 10.1111/1475-6773.12098 pmid: 23910019

16 Jacobs JC, Jarvik JG, Chou R, etal. Observational study of the downstream consequences of inappropriate MRI of the lumbar spine. J Gen Intern Med 2020;35:3605-12. doi: 10.1007/s11606-020-06181-7 pmid: 32989711

17 Hall AM, Scurrey SR, Pike AE, etal. Physician-reported barriers to using evidence-based recommendations for low back pain in clinical practice: a systematic review and synthesis of qualitative studies using the Theoretical Domains Framework. Implement Sci2019;14:49. doi: 10.1186/s13012-019-0884-4 pmid: 31064375

18 Chou R, Deyo R, Friedly J, etal. Nonpharmacologic therapies for low back pain: a systematic review for an American College of Physicians Clinical Practice Guideline. Ann Intern Med 2017;166:493-505. doi: 10.7326/M16-2459 pmid: 28192793

$19 \mathrm{Lim}$ YZ, Chou L, Au RT, etal. People with low back pain want clear, consistent and personalised information on prognosis, treatment options and self-management strategies: a systematic review. J Physiother 2019;65:124-35. doi: 10.1016/j.jphys.2019.05.010 pmid: 31227280

20 Bardin LD, King P, Maher CG. Diagnostic triage for low back pain: a practical approach for primary care. Med J Aust 2017;206:268-73. doi: 10.5694/mja16.00828 pmid: 28359011

21 Traeger A, Buchbinder R, Harris I, Maher C. Diagnosis and management of low-back pain in primary care. CMA/2017;189:E1386-95. doi: 10.1503/cmaj.170527 pmid: 29133540

22 Jenkins HJ, Moloney NA, French SD, etal. Using behaviour change theory and preliminary testing to develop an implementation intervention to reduce imaging for low back pain. BMC Health Serv Res 2018;18:734. doi: 10.1186/s12913-018-3526-7 pmid: 30249241

23 Braeuninger-Weimer K, Anjarwalla N, Pincus T. Discharged and dismissed: A qualitative study with back pain patients discharged without treatment from orthopaedic consultations. Eur J Pain 2019;23:1464-74. doi: 10.1002/ejp.1412 pmid: 31069890

This is an Open Access article distributed in accordance with the Creative Commons Attribution Non Commercial (CC BY-NC 4.0) license, which permits others to distribute, remix, adapt, build upon this work non-commercially, and license their derivative works on different terms, provided the original work is properly cited and the use is non-commercial. See: http://creativecommons.org/licenses/by$\mathrm{nc} / 4.0 \%$. 